\title{
Post-Traumatic Subdural Higroma: A Case Report
}

\author{
Osman Celbiş, Mucahit Oruç, Mustafa Doğan, Bedirhan Sezer Öner, Cihan Göktürk, Nusret Ayaz, Çağatay Önal S and Semih Petekkaya* \\ Council of Forensic Department, Malatya, Yeşiltepe/ Yeşilyurt, Turkey
}

\section{Introduction}

Evaluations of blunt head trauma are often made in forensic medicine practice. There has been accumulated detailed knowledge on the subject of subarachnoid haemorrhage, epidural and subdural haematoma which occur related to these injuries. However, another complication, which is less frequently seen and about which less knowledge has been gathered is traumatic subdural higroma [1]. Although the formation of traumatic subdural higroma is not fully understood, it has beeen reported as a clinical event which develops as a result of cerebral spinal fluid (CSF) leaking into the subdural space because of arachnoid membrane tears following trauma [2,3]. Although generally seen at small dimensions clinically, a small proportion reach a large size and show an effect of pressure on the brain tissue. When a pressure effect is created, a surgical decompression procedure must be applied as it is a life-threatening feature [3].

The case is here presented of subdural higroma which occurred without an additional intracranial lesion as a result of blunt head trauma, which is rarely encountered in forensic medicine practice.

\section{The Case}

A 76-year old male presented at the Emergency Department with blunt head trauma and was reported to have lost consciousness. No neurological deficit was determined in the neurological examination. Ecchymosis was determined bilaterally in the infra-supraorbital region of the eyes and oedema in the nasal region. In the physical examination, no other traumatic clinical event was recorded. On examination of the brain computed tomography (CT) scan taken on the day of the event, it was seen that there was no osseous or parenchymal pathology and both frontal extra-axial CSF spaces were wide (Figure 1). The patient was discharged with recommendations. In the medico-legal evaluation made by the physician treating the patient, the clinical status of the patient was reported as exposure to mild trauma.

The patient presented at the Emergency Department again 5 days after the initial trauma, with complaints of headache and nausea. On CT examination, diagnosis was made of bifrontoparietal subdural higroma

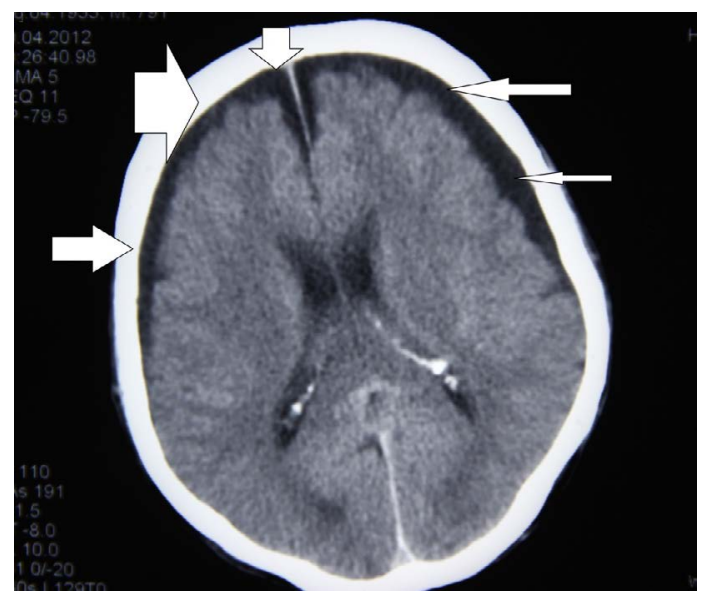

Figure 1: Brain computed tomography (CT) scan.

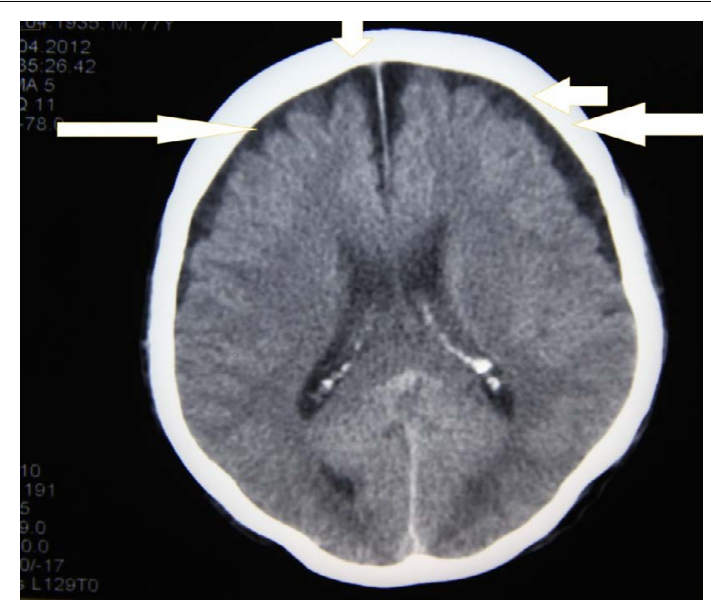

Figure 2: CT examination and diagnosis of bifrontoparietal subdural higroma.

and the patient was admitted for surgery (Figure 2). In the operating notes it was reported that by opening burrholes in both parietal regions the pressurised subdural higroma was drained and as iatrogenic pneumocephaly was determined during the follow-up period, the suture areas were opened with the use of the burrholes and the subdural space was seen to be full of fluid. At 2 months postoperatively, as a result of tests made due to complaints of headache, a diagnosis was made of bifrontoparietal subdural empyema. In the operating notes it was reported that the right frontotemporal subdural empyema was drained, craniectomy was applied by widening the left frontal burrhole, duraplasty was applied, the right frontoparietotemporal flap was raised and the subdural hamatoma was drained.

A medico-legal evaluation of the blunt head trauma was requested, by the official suthritres. In the evaluation, it was stated that the patient had a pain in his foot, was only able to eat a half portion of food, had complaints of forgetfulness, fatigue and dizziness, and was only able to walk for 10 minutes, but did not experience fainting or seizures, was not on any permanent medication and had no complaints of micturation or defecation. In the physical examination, an area of skin depression $2 \mathrm{~cm}$ in diameter was seen in the parietal region, a C-shaped area of skin depression $14 \mathrm{~cm}$ in length was seen in the left temporal region, there was no gait impairment and joint range of movement and muscle strength were full. In the evaluation of short-term memory, it was

*Corresponding author: Semih Petekkaya, Council of Forensic Department Malatya, Yeşiltepe/ Yeşilyurt, Turkey, Tel: +904223410660; E-mail: semihpetekkaya@ gmail.com

Received June 04, 2015; Accepted June 27, 2015; Published July 08, 2015

Citation: Celbiş O, Oruç M, Doğan M, Sezer Öner B, Göktürk C, et al. (2015) Post-Traumatic Subdural Higroma: A Case Report. J Trauma Treat 4: 260. doi:10.4172/2167-1222.1000260

Copyright: ( 2015 Celbiş O, et al. This is an open-access article distributed under the terms of the Creative Commons Attribution License, which permits unrestricted use, distribution, and reproduction in any medium, provided the original author and source are credited. 
determined that the patient could not repeat given words after a certain time. It was reported in the medico-legal evaluation that subdural higroma, which could be considered to have developed as a result of the blunt head trauma had led to a life-threatening situation.

\section{Discussion and Conclusion}

Subdural higroma is an accumulation of CSF in the subdural space in an acute or chronic process, which is generally secondary to trauma. Although the pathophysiology has not been fully explained, the most widely accepted theory has been reported as tears occurring in the arachnoid membrane acting as a one-way flap preventing the absorption of fluid which has leaked into the subdural space [1]. Traumatic subdural higroma seen in the late stage of $6 \%$ of cases with head trauma is an uncommon clinical event. The majority of subdural higroma are asymptomatic and at the advanced stage extend towards the region of brain effusion and disappear with absorption [4]. Just as advanced subdural higroma which have created a pressure effect may lead to neurological sequelae, they can cause life-threatening clinical events [1].

Subdural higroma are generally more widely seen in males, the elderly and those with findings of brain atrophy [3-6]. The current case was a 76-year old male and on examinaton of the brain CT taken on the day of the trauma, both frontal extra-axial CSF spaces were determined as wide. As the patient was elderly with findings of brain atrophy, it was considered that by creating a potential area in the cranial cavity, the subdural higroma formed and accumulated easily. Following trauma, patients generally present with complaints such as a moderate level of mental status, progressive headache and nausea and vomiting. Stupor or coma is seen at a lower rate [1]. These findings are associated with an increase in cranial pressure. It has been reported that traumatic subdural higroma will occur 1-24 days after trauma and that a resolution is sought 6-36 days later. In cases followed up conservatively because of small tears, the traumatic subdural higroma can be seen to have reduced in size or disappeared within 9 months [5]. In the case reported here, the subdural higroma was determined when the patient presented with complaints of headache and nausea 5 days after the initial trauma and as result of the clinical status and radiological examination, surgery was applied.

Previous studies have reported that subdural higroma could occur generally 2 weeks after trauma and because it could lead to chronic subdural haematoma, clinical follow-up and examinations are necessary $[3,4,6-8]$. In the case presented here, the medico-legal evaluation on theday of the event reported the clinical status of the patient as exposure to mild trauma and the diagnosis of subdural higroma was made on presentation 5 days after the event. Reports prepared at the time of an event without taking clinical follow-up and examinations into consideration can lead to rarely seen late complications of trauma being missed such as traumatic subdural higroma and thereby omissions in the medico-legal evaluation reports. Therefore, medico-legal evaluation reports to be made about an individual must be prepared taking into consideration the late complications of trauma.

For patients presenting with blunt head trauma, the medical records must be prepared fully and in detail, through clinical follow-up and repeated examinations, particularly for high-risk groups (elderly, disabled, etc). Thus, the identification of rarely seen late complications of trauma, the establishment of a link with causes of the incident and the application of a sound medico-legal evaluation can be provided.

\section{References}

1. Herold TJ, Taylor S, Abbrescia K, Hunter C (2004) Post-Traumatıc Subdural Hygroma: Case Report. J Emerg Med 27: 361-366.

2. Akköse Ş (2000) Acil Serviste Kafa Travmalı Hastaya Yaklaşım; Acil Tıp Dergisi 3: $83-93$

3. Zanini MA, de Lima Resende LA, de Souza Faleiros AT, Gabarra RC (2008) Traumatic Subdural Hygromas: Proposed Pathogenesis Based Classification. J Trauma 64: 705-713.

4. Park SH, Lee SH, Park J, Hwang JH, Hwang SK, et al. (2008) Chronic subdural hematoma preceded by traumatic subdural hygroma. J Clin Neurosci 15: 868872 .

5. Ishibashi A, Yokokura Y, Miyagi J (1994) Clinical Analysis Of Nineteen Patients With Traumatic Subdural Hygromas. Kurume Med J 41: 81-85.

6. Zanini MA, Resende LA, Freitas CC, Yamashita S (2007) Traumatıc Subdura Hygroma, Five cases with changed density and spontaneous resolution. Arq Neuropsiquiatr 65: 68-72

7. Lee KS, Bae WK, Bae HG, Yun IG (2000) The Fate of Traumatic Subdura Hygroma in Serial Computed Tomographic Scans. J Korean Med Sci 15: 560568 .

8. Mitsuhiro H, Tetsumori Y, Junkoh Y, Masayuki S, Sadahiro S (1992) Traumatic Subdural Hygroma: Pathology and Meningeal Enhancement on Magnetic Resonance Imaging. Neurosurgery 31: 580-585. 